\title{
A Study of Serum Lipids in Nephrotic Syndrome in Children
}

\author{
Dr. Dnyanesh DK ${ }^{1}$, Dr. Suma Dnyanesh ${ }^{2}$, Dr. Varadaraj Shenoy ${ }^{3}$ \\ ${ }^{1}$ Department of Paediatrics*, KLE University's Jawaharlal Nehru Medical College, Belgaum 590010, \\ Karnataka, India \\ ${ }^{2}$ Department of Anatomy, KLE University's Jawaharlal Nehru Medical College, Belgaum 590010, Karnataka, \\ India ${ }^{3}$ Department of Paediatrics, Rajiv Gandhi University's Father Muller Medical College, Mangalore \\ 575002, Karnataka, India.
}

\begin{abstract}
Background and Objectives: Hyperlipidemia is a common finding in nephrotic syndrome. There is increased total Cholesterol, $L D L, V L D L$ and low or normal HDL. Hyperlipidemia is usually observed during the active phase of disease and disappears with resolution of proteinuria. But in relapsing cases, it may persist and may increase risk of atherosclerosis in later life. Hence serial monitoring of lipids is required to predict prognosis. Hence, our study is an attempt to know derangement of serum lipids in nephrotic syndrome.

Methods: A prospective study included 30 children with nephrotic syndrome, aged between 0-12 years. They were clinically examined and lipid profile was done in each case before steroid therapy, after one month of therapy and at the end of therapy. 10 children without liver and kidney disorders were taken as controls.

Results: In all cases, there were increased mean total cholesterol, $L D l, V L D L$ and triglyceride. However there was no significant change in HDL. With steroid treatment, in first episode nephrotic syndrome, there was highly significant reduction in the mean levels of pretreatment total cholesterol, $L D L(p=0.001)$ and triglycerides $(p=$ 0.016). However in relapse nephrotic syndrome, even at end of treatment, serum lipids were found to be persistently high.

Conclusion: Our study concludes that, there is generalized hyperlipidemia (except HDL) and hypoalbuminemia. The serum cholesterol level in first episode nephrotic syndrome reaches normal at the end of steroid therapy. But in cases of relapse, there is persistent elevation in the cholesterol levels, which may predispose to development of atherosclerosis and progression to chronic renal failure
\end{abstract}

Key words: Hyperlipidemia, nephrotic syndrome, lipoproteins, ISKDC treatment, statins.

\section{Introduction}

Hyperlipidemia has been recognized as a common finding in nephrotic patients since 1917, when hypercholesterolemia was described as a feature of nephrotic syndrome

Although pathophysiological aspects of hyperlipidemia have not been completely identified, hypoalbuminemia, increased lipoprotein synthesis and decreased lipoprotein lipase activity are described by various workers ${ }^{[2]}$. Some degree of correlation between lipids and serum albumin has been suggested by Thomas et al. ${ }^{[3]}$ and between lipidemia and oedema by Peters et al.

Lipoproteins play an important role in the transport of plasma lipids; their increase or alteration in various fractions may be responsible for hypercholesterolemia, in nephrotic syndrome ${ }^{[2]}$. There is increased total cholesterol, LDL cholesterol, VLDL cholesterol and triglycerides and normal or low HDL cholesterol . However, in Indian children, the degree of hyperlipidemia is not high as in western children ${ }_{[6,7]}^{\text {. More recently }}$

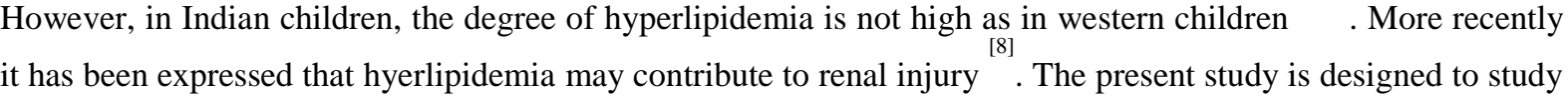
the derangement of serum lipids in nephrotic syndrome and to know whether any correlation exists between serum lipids and albumin.

- To study the derangement of serum lipids

II. Objectives

- To do serial estimations of lipids to assess when the serum lipids return to normal.

\section{Methodology}

Data included 30 cases of children with nephrotic syndrome, admitted for the first time in the pediatric wards of Fr. Muller Medical College Hospital, for this prospective study. 10 children without liver and kidney disorders were taken as control group. 


\subsection{Method of collection of Data:}

30 nephrotic syndrome cases were clinically examined and following investigations were performed in each case, before steroid therapy (ISKDC Regimen), after one month of steroid therapy and at the end of therapy.

1) Serum total cholesterol: was measured by Enzymatic method

Normal serum cholesterol: $150-250 \mathrm{mg} / \mathrm{dl}$

2) Serum HDL cholesterol: was measured by "Phosphotungstate method.

Normal HDL - Cholesterol : 30 - $70 \mathrm{mg} / \mathrm{dl}$.

3) Serum LDL cholesterol: If the value of Triglycerides is known, LDL-cholesterol can be calculated based on Friedewald's equation.

LDL - chol mg/dl: Total CHOL - TRIGLYCERIDES - HDL - CHOL

4) Serum Triglycerides; was measured by enzymatic colorimetric method

Normal Serum Triglycerides: Male: $60-165 \mathrm{mg} / \mathrm{dl}$

Female: $40-140 \mathrm{mg} / \mathrm{dl}$

5) Serum VLDL : Was measured by Enzymatic method.

6) Serum Albumin : Was measured by Photometric method

Normal value is $3.5-5.0 \mathrm{gm} / \mathrm{dl}$

3.2 Inclusion Criteria: All infants and children between 0-12 years of age suffering from nephrotic syndrome.

\subsection{Exclusion Criteria:}

- Children with liver disorders.

- Children with oedema due to Kwashiorkor

- Children with oedema due to CCF

- Children suffering from kidney diseases other than nephrotic syndrome.

Data analysis: was done by Mann Whitney ' $U$ ' test, Wilcoxon signed rank sum test and by Pearson correlation test.

3.4 Treatment Protocol ${ }^{[9]}$ : International study group on kidney diseases in children(ISKDC) regimen.

- Prednisolone $60 \mathrm{mg} / \mathrm{m} /$ day in 3 divided doses for 4 weeks followed by prednisolone $40 \mathrm{mg} / \mathrm{m}$ on alternate days for the next 4 weeks

\subsection{Definition:}

- Steroid resistant: Failure to achieve response despite 4 weeks of steroid therapy

- Relapse: Urinary protein $3+$ or more on 3 consecutive days with or without edema, while in remission.

\section{Results}

Our study shows that in nephrotic syndrome, there is generalized hyperlipidemia and hypoalbuminemia. Although hyperlipidemia is most marked when serum albumin is low, yet no definite correlation can be established between the degree of hypoalbuminemia and rise of lipids.

The present study also shows that serum cholesterol level in first episode of nephrotic syndrome reaches normal value at the end of steroid therapy. However in cases of relapses, there is persistent elevation in the cholesterol levels, which may predispose to the development of atherosclerosis and progression of chronic renal failure. Hence there is a rationale for treatment. Further prospective control studies in children evaluating efficacy and safety of lipid lowering drugs are needed.

Total number of cases $=30$

Total number of controls $=10$

TABLE 1: SERUM LIPIDS IN NEPHROTIC SYNDROME

\begin{tabular}{|l|l|l|l|l|}
\hline & Range $\mathbf{( m g} \%)$ & Mean $\mathbf{( m g \% )}$ & Std. Deviation & P value \\
\hline Total cholesterol & $253-676$ & 422.61 & 198.81 & $\mathrm{P}=0.001$ \\
\hline LDL cholesterol & $190-577$ & 319.10 & 157.17 & $\mathrm{P}=0.001$ \\
\hline VLDL cholesterol & $23-107$ & 54.53 & 21.17 & $\mathrm{P}=0.001$ \\
\hline HDL cholesterol & $26-70$ & 45.56 & 20.52 & $\mathrm{P}=0.078$ \\
\hline Triglycerides & $113-555$ & 284.06 & 107.12 & $\mathrm{P}=0.001$ \\
\hline
\end{tabular}


In this study, the total cholesterol, LDL, VLDL, triglycerides are significantly higher than those in controls $(\mathrm{P}=$ 0.001). However there is no statistically significant change seen in HDL cholesterol $(P=0.078)$.

TABLE 2 : LIPIDS IN CONTROL

\begin{tabular}{|c|c|c|}
\hline LIPIDS & RANGE $(\mathrm{mg} \%)$ & MEAN (mg\%) \\
\hline Total cholesterol & $151-250$ & 190.10 \\
\hline LDL cholesterol & $86-170$ & 119.50 \\
\hline VLDL cholesterol & $36-50$ & 43.30 \\
\hline HDL cholesterol & $45-54$ & 48.30 \\
\hline Triglycerides & $76-120$ & 92.70 \\
\hline
\end{tabular}

There were 10 controls. Their ages varied from $21 / 2$ to 12 years. All had normal renal functions.

TABLE 3: SERUM ALBUMIN IN NEPHROTIC SYNDROME

\begin{tabular}{|l|l|l|l|l|}
\hline Group & $\mathrm{N}$ & Mean $(\mathrm{gm} \%)$ & Std. Deviation & $\mathrm{Z}$ \\
\hline Study & 30 & 2.52 & 3.39 & 4.38 \\
\hline Control & 10 & 4.03 & 0.15 & $\mathrm{P}=0.001$ \\
\hline
\end{tabular}

This table shows that the serum albumin in nephrotic syndrome is significantly lower, than in controls $(\mathrm{P}=$ $0.001)$

TABLE 4: COMPARISON OF SERUM ALBUMIN AND SERUM CHOLESTEROL

\begin{tabular}{|l|l|l|l|l|l|}
\hline Albumin $(\mathrm{g} \%)$ & $\mathrm{N}$ & \multicolumn{1}{|c|}{$\begin{array}{c}\text { Mean tot. chol } \\
(\mathrm{mg} \%)\end{array}$} & Std. deviation & H & P value \\
\hline $1-1.5$ & 7 & 516.66 & 292.13 & & \\
\hline $1.6-2$ & 15 & 362.55 & 146.72 & & 0.537 \\
\hline $2.1-2.5$ & 8 & 336.25 & 191.91 & 1.24 & \\
\hline
\end{tabular}

The table shows an inverse relation between serum albumin and cholesterol. However the correlation is not statistically significant $(\mathrm{P}=0.537)$.

TABLE 5: LIPID PROFILE IN FIRST EPISODE NEPHROTIC SYNDROME AFTER 4 WEEKS OF TREATMENT

\begin{tabular}{|l|c|c|c|}
\hline \multicolumn{1}{|c|}{ Lipids } & Mean(mg/dl) & Std.dev & P value \\
\hline Total Chol & 201.77 & 41.341 & 0.001 \\
\hline LDL Chol & 151.13 & 37.173 & 0.001 \\
\hline VLDL Chol & 52.51 & 5.243 & 1.078 \\
\hline HDL Chol & 45.98 & 3.023 & 0.518 \\
\hline Triglycerides & 231.19 & 20.177 & 0.537 \\
\hline
\end{tabular}

In first episode nephrotic syndrome, after 4 weeks of steroid treatment, there was significant reduction in the levels of pretreatment mean total cholesterol (mean $=201.77 \mathrm{mg} \%, \mathrm{p}=0.001)$ and mean LDL Cholesterol (mean $=151.13 \mathrm{mg} \%, \mathrm{p}=0.001$ ) where as no significant change was observed in HDL Cholesterol, VLDL Cholesterol and triglyceride level.

\section{TABLE 6: LIPID PROFILE IN RELAPSE EPISODE NEPHROTIC SYNDROME AFTER 4} WEEKS OF TREATMENT

\begin{tabular}{|c|c|c|c|}
\hline Lipids & Mean(mg/d) & Std. deviation & P value \\
\hline Total & 541.00 & 102.141 & 0.001 \\
\hline LDL & 337.04 & 81.723 & 0.001 \\
\hline VLDL & 64.01 & 11.341 & 0.001 \\
\hline HDL & 44.21 & 3.143 & 0.527 \\
\hline Triglycerides & 351.13 & 30.321 & 0.001 \\
\hline
\end{tabular}


In relapse nephrotic syndrome, even after 4 weeks of steroid treatment, there was no significant change in the mean levels of pretreatment total cholesterol, LDL Cholesterol, HDL Cholesterol, VLDL Cholesterol and triglycerides

TABLE 7: POSTTREATMENT LIPID PROFILE IN FIRST EPISODE NEPHROTIC SYNDROME

\begin{tabular}{|c|c|c|c|}
\hline Lipids & Mean $(\mathbf{m g}$ \%) & Std. deviation & P value \\
\hline Total chol & 166.27 & 33.1815 & 0.001 \\
\hline LDL chol & 112.17 & 22.6090 & 0.001 \\
\hline VLDL chol & 49.05 & 5.2715 & 0.060 \\
\hline HDL chol & 48.23 & 3.0203 & 0.070 \\
\hline Triglycerides & 171.41 & 31.8607 & 0.016 \\
\hline
\end{tabular}

At the end of steroid therapy, in first episode nephrotic syndrome, there was statistically highly significant reduction in the mean levels of pretreatment total cholesterol (mean $=166.27 \mathrm{mg} \%, \mathrm{p}=0.001)$ and LDL

Cholesterol(mean $=112.17 \mathrm{mg} \%, \mathrm{p}=0.001$ ).There was also significant reduction in the level of mean triglycerides (mean $=171.41 \mathrm{mg} \%, \mathrm{p}=0.016$ ). No significant change observed in mean VLDL Cholesterol. However there was some increase in mean HDL Cholesterol but was not statistically significant.

TABLE 8: POST-TREATMENT LIPID PROFILE IN RELAPSE NEPHROTIC SYNDROME

\begin{tabular}{|l|c|c|c|}
\hline \multicolumn{1}{|c|}{ Lipids } & Mean $(\mathbf{m g} \%)$ & Std. deviation & P value \\
\hline Total chol & 537.00 & 112.131 & 0.001 \\
\hline LDL chol & 325.34 & 88.027 & 0.001 \\
\hline VLDL chol & 63.78 & 12.013 & 0.001 \\
\hline HDL chol & 43.17 & 3.132 & 0.560 \\
\hline Triglycerides & 324.13 & 57.107 & 0.001 \\
\hline
\end{tabular}

In relapse nephrotic syndrome, even at the end of steroid treatment, there was no significant reduction in the mean levels of pretreatment total cholesterol, LDL Cholesterol, VLDL Cholesterol and triglycerides. And also no significant increase in HDL Cholesterol.

\section{Discussion}

'Hippocrates' first observed that, "when bubbles settle on the surface of urine they indicate disease of the kidney". The nephrotic syndrome is not a single disease. It is a clinical state characterized by "Heavy proteinuria and hypoalbuminemia, often associated with edema, hyper cholosterolemia, and generalized hyper lipidemia" ${ }^{[9]}$.

Lipoprotein plays an important role in the transport of plasma lipids. They are Chylomicrons, VLDL, LDL, and HDL $^{[2]}$.

The present study consists of 30 cases of children with nephrotic syndrome aged between 0 to 12 years and 10 normal children without liver and kidney disorders were taken as controls. In the present study $73.3 \%$ children were below 6 years of age and it was more common in male than in females $(3: 2)$.

\section{Serum Lipids in Nephrotic Syndrome}

In our study there was significant rise in total cholesterol (mean $=422.61 \mathrm{mg} \%)$, LDL (mean $=319.10$ $\mathrm{mg} \%)$, VLDL $($ mean $=54.53 \mathrm{mg} \%)$ and triglycerides (mean $=284.06 \mathrm{mg} \%)$ than normal and was highly significant $(\mathrm{P}=0.001)$. HDL cholesterol was within normal limits (mean=45.56 $\mathrm{mg} \%)$. The mean serum cholesterol in relapse cases $($ mean $=568.52 \mathrm{mg} \%)$ was significantly higher than first episode nephrotic syndrome cases $($ mean $=343.4 \mathrm{mg} \%, \mathrm{p}=0.001)$ and the mean serum cholesterol in steroid resistant cases was much higher than steroid sensitive cases $(\mathrm{p}=0.001)$. Arije et al also observed persistent rise in serum lipids in frequent relapse [10]

We noticed that the degree of lipid increase was not that high as reported by Western workers. Milne reported that the total cholesterol in nephrotic syndrome may be higher than $1000 \mathrm{mg} \%$. In our study the mean total cholesterol was $422.61 \mathrm{mg} \%$ and highest value was $676 \mathrm{mg} \%$. Banerjee et al in his study observed 
that the mean total cholesterol was $341 \mathrm{mg} \%$ and the highest value was $641 \mathrm{mg} \%{ }^{[6]}$. Thus we observed low serum lipids in Indian children.

We observed a positive correlation between serum total cholesterol and LDL cholesterol and was statistically highly significant $(\mathrm{P}=0.001)$. David et al also found positive correlation between total cholesterol and LDL cholesterol $(\mathrm{p}=0.001)^{[5]}$. Benakappa et al also had similar observations ${ }^{[7]}$.

\section{Relation between Albumin and Serum Lipids in Nephrotic Syndrome}

In our study, we observed an inverse correlation between albumin and cholesterol. When albumin was too low (range $1.0-1.5 \mathrm{gm} \%$ ), the serum cholesterol was very high (mean $=516.66$ ) and vice versa.However the correlation is not statistically significant $(\mathrm{P}=0.537)$. Heymann et al, found no correlation between the developmental of hyperlipidemia and hypoalbuminemia and postulated that the severity of hyperlipidemia is related to the amount of nephrotic kidney tissue present ${ }^{[12]}$. Thomas et al found correlation between serum cholesterol and albumin and did not find correlation between serum cholesterol and globulin and total protein ${ }^{\text {[3] }}$. Friedman and Byers postulated that hypoalbuminemia causes hyperlipidemia ${ }^{[13]}$.

In the present study, we observed a direct relation between serum albumin and HDL Cholesterol. When serum albumin was too low (1.0-1.5gm\%), the HDL Cholesterol was also low(mean=42.13mg\%)where as when albumin was between 2.1-2.5gm\%,the mean HDL Cholesterol was $45.27 \mathrm{mg} \%$ but the correlation was not statistically significant $(\mathrm{p}=0.537)$.Mallik et al also had similar observations. We also observed an inverse relation between serum albumin and VLDL cholesterol but it was not statistically significant $(\mathrm{p}=0.578)^{[14]}$.

\section{Response of Serum Lipids to Steroid therapy}

In our study, $90 \%$ cases were steroid sensitive and $10 \%$ were steroid resistant. All cases were treated with short term high dose prednisolone (ISKDC) regimen.

We observed different response in first episode nephrotic syndrome and relapse cases. In first episode cases, serum cholesterol was high $($ mean $=343.4 \mathrm{mg} \%)$ before treatment. However, serum cholesterol subsequently reduced to normal at the end of $(8$ weeks $)$ treatment $(\mathrm{P}=0.001)$ whereas in case of relapses serum cholesterol reduced marginally but it was persistently high $(\mathrm{P}=0.001)$. Merouani et al observed hyperlipidemia during the active phase of the disease and disappeared with resolution of the proteinuria and was persistently abnormal in frequently relapsing children ${ }^{[15]}$. Tsukahara et al observed that children with frequently relapsing nephrotic syndrome have prolonged periods of hypercholesterolemia ${ }^{[16]}$. Querfeld used statins in his study and observed $30-40 \%$ reduction in the total cholesterol ${ }^{[17]}$. Buyokceliket al observed significant reduction in the total cholesterol with statins in adult patients with nephrotic syndrome ${ }^{[18]}$.

\section{Conclusion}

Our study shows that in nephrotic syndrome, there is generalized hyperlipidemia and hypoalbuminemia. Although hyperlipidemia is most marked when serum albumin is low, yet no definite correlation can be established between the degree of hypoalbuminemia and rise of lipids.

The present study also shows that serum cholesterol level in first episode of nephrotic syndrome reaches normal value at the end of steroid therapy. However in cases of relapses, there is persistent elevation in the cholesterol levels, which may predispose to the development of atherosclerosis and progression of chronic renal failure. Hence there is a rationale for treatment. However the benefits of treatment with lipid lowering drugs have not been proven in children. Further prospective control studies in children evaluating efficacy and safety of lipid lowering drugs are needed.

\section{References}

[1] A.A Epstein, The nature and treatment of Nephrosis, JAMA 69, 1917, 444-47.

[2] B. Bhandari, S.L.Mandowara, Lipoprotein profile in nephrotic syndrome, Indian pediatrics, 17, 1980, $416-19$.

[3] E.M.Thomas, A.H Rosenblum, H.B Lander, R Fisher, Relationship between blood lipid and blood protein levels in nephrotic syndrome, Amer J Dis. Child, 81, 1951, 207.

[4] J.P Peters, E.B Man, The inter relationship of Serum lipids in patients with diseases of kidneys, J Clin Invest, 22, $1943,721$.

[5] C.W David, D.B Bernard, Lipid abnormalities in the nephrotic syndrome, Am J Kidney Dis, 23(3), 1994, 331-46.

[6] S.K Banerjee, A.K Sarkar, K.S Chugh, V.K Bansal, P.N Chhuttani, Serum lipids in nephrotic syndrome, JAPI, 71, $1982,651-57$.

[7] D.G Benakappa, A Subba Rao, N.S.C Sastry, Low density lipoprotein levels in children with nephrotic syndrome, Indian pediatrics, 13 (4), 1976, 287-89

[8] J.F Moorhead, M.K Chan, A.M Nahas, Z Varghese, Lipid nephrotoxicity in chronic progressive glomerular and tubulo interstitial disease, Lancet , 2, 1982, 1309-11.

[9] C.M Edelmann, J Bernstein, L.B Travis, S.R Meadow, Pediatric kidney diseases (New York, Little brown Publisher; 1992). 
[10] A Arije, R.T Erasmus, S.A Anjorin, Plasma lipids and lipoproteins cholesterol distributions in nephrotic syndrome patients during short term steroid treatment. Cent Afr J Med, 39 (10), 1993, 211-5.

[11] M Milne, Biochemical disorders in human disease ( 2 ed. London: Churchill Ltd: 1976).

[12] W Heymann, L.W Mathews, Studies on the casual role of hypoabluminemia in experimental nephrosis. J Clin Invest, $37,1958,808$.

[13] M Friedman, Roseman, Byers, Hyperlipidemia in nephrotic syndrome. J Clin Invest 33, 1954, 1103

[14] N.P Mallik, M.C Stone, Chopra, Hyperlipoproteinemias in nephrotic syndrome. Lancet 1, $1973,317$.

[15] A Merouni, E Levy, J.G Mongeace, M Lambert, E.E Delvin, Hyperlipidemic profiles during remission in childhood idiopathic nephrotic syndrome. Clin Biochem, 36 (7), 2003, 571-4.

[16] H Tsukahara, Harukis, M Hiroka, Horic, M Sudo, Persistent hypercholesterolemia in frequently relapsing steroid responsive nephrotic syndrome. J Paediatr Child Health 33 (3), 1997,253-5.

[17] U Querfeld, Should hyperlipidemia in children with nephrotic syndrome be treated? Pediatr Nephrol 13 (1), $1999,77-84$.

[18] M Buyukcelik, A Anarat, A Noyas, A Ozcl, R Anarat, M Dikmen et al. The effects of gemfibrozil on hyperlipidemia in children with persistent nephrotic syndrome, Turk J pediatrics 44 (1), 2002, 40-4. 